\title{
Funcionalidades, Características e Limitações Das Plataformas De Participação e Colaboração: Uma Análise Comparativa
}

\section{Functionalities, Characteristics, And Limitations Of Participation Platforms And Collaboration: A Comparative Analysis}

\author{
José Antônio Pedro dos Santos ${ }^{1}$, Jorge da Silva Correia Neto ${ }^{1}$, Ellen Souza ${ }^{1}$
}

\author{
${ }^{1}$ Universidade Federal Rural de Pernambuco, UFRPE, Brasil \\ Correspondência: Jorge da Silva Correia Neto. Endereço: Endereço: Rua Manuel de Medeiros, s/n - Dois Irmãos, \\ Recife - PE, 52171-900 Telefone: (81) 3320-6000 E-mail: jorgecorreianeto@gmail.com
}

Recebido: 30 de novembro de 2017 Aceito: 16 de dezembro de 2017 Publicado: 31 de dezembro de 2017

DOI: http://dx.doi.org/10.21714/1679-18272017v15Ed.p147-156

\begin{abstract}
Resumo
O aumento na utilização das novas tecnologias da informação e da comunicação pela sociedade e a migração da informação baseada em papel para mídias eletrônicas proporcionam uma manipulação mais eficiente das informações, oferecendo novas formas de interação entre as pessoas e impulsionando instituições governamentais a oferecerem novos canais de comunicação para a sociedade. Assim, mais e mais plataformas têm surgido com essas características, que são chamadas de plataformas participação e colaboração eletrônica, ou de e-participação e de e-colaboração, e que visam ampliar a participação cidadã nas tomadas de decisões da administração pública. Visando avaliar o quão colaborativas e interativas são tais ferramentas, foi utilizado o modelo i3C para analisar as plataformas de e-participação e e-colaboração governamentais disponibilizadas no Brasil. Com os resultados obtidos nesta pesquisa, foi possível identificar as plataformas que são mais interativas, e que tem maior adesão da população brasileira.
\end{abstract}

Palavras-chave: Participação eletrônica, Colaboração eletrônica, Modelo i3C.

\begin{abstract}
The increasing use of new information and communication technologies in today's society and the migration of paper-based information to electronic media provide more efficient manipulation of information, offering new forms of interaction between people, pushing government institutions to new channels of communication for society. Thus, platforms with these characteristics are emerging, which are called platforms for electronic participation and electronic collaboration, or for e-participation and e-collaboration, whose vision is to intensify citizen participation in public administration decision-making. In order to evaluate how collaborative these tools are, the $\mathrm{i} 3 \mathrm{C}$ model was used to analyze the level of interactivity of the e-participation and government collaboration platforms available in Brazil. Aiming to analyze the level of interactivity of e-participation and ecollaboration platforms available in Brazil. With the results obtained in this research, it was possible to identify the platforms that are more interactive, and that have greater interest of the Brazilian population.
\end{abstract}

Keywords: Electronic participation, Electronic collaboration, i3C model.

Esta obra está licenciada sob uma Licença Creative Commons Attribution 3.0.

\section{Introdução}

O aumento na utilização das novas tecnologias da informação e da comunicação (TICs) pela sociedade e a migração da informação baseada em papel para mídias eletrônicas (DINIZ et al., 2009) têm proporcionado uma manipulação mais eficiente e transparente das informações, oferecendo novas formas de interação entre as pessoas. Essa massiva utilização por parte da população também vem impulsionando muitas instituições governamentais a oferecerem novos canais de comunicação para a sociedade, visando interagir com os seus cidadãos.

Nesse contexto já nasceram muitas ferramentas de participação e colaboração eletrônica, também chamadas de 
plataformas de e-participação e de e-colaboração. De acordo com Macintosh (2004), o termo e-participação, do inglês, e-participation, é constituída pelo elemento " $e$ ", de eletrônico e tem uma associação com e-government e e-governance, e também de "participation", que juntos, referem-se o uso das novas TICs visando ampliar a participação cidadã nas tomadas de decisões da administração pública, promovendo a participação popular no processo democrático de tomada de decisão (MACINTOSH, 2004; MEDAGLIA, 2012), de forma eletrônica.

Já a e-collaboration surge com a premissa de "construir em conjunto", e também é constituída pelo termo "e", de eletrônico, para indicar o uso de ferramentas eletrônicas de forma colaborativa na construção ou aprimoramento de um projeto, como os sistemas que são desenvolvidos por um grupo de pessoas que trabalham em projetos específicos e que fazem parte da construção ou aprimoramento do mesmo projeto como um todo. Um bom exemplo disso é o desenvolvimento de softwares livres, onde os engenheiros de software têm a liberdade de cooperar ativamente com seus pares para modificar o programa, de modo que toda a comunidade se beneficie.

Através destas plataformas, o cidadão pode fiscalizar, discutir, sugerir, reclamar, expor suas ideias e até se disponibilizar para resolver alguns problemas. Por isso o governo brasileiro também vem investindo na criação de novos mecanismos para ampliar os meios de participação eletrônica dos cidadãos, com o intuito de inclú́-los no processo democrático, objetivando ouvir seus anseios e opiniões sobre diversas temáticas (FREIRE et al., 2011).

Visando avaliar o quão colaborativas são essas ferramentas governamentais disponibilizadas pelos governos, a presente pesquisa buscou na literatura os modelos de colaboração mais utilizados. Assim, levando em consideração o que aponta o mapeamento sistemático de (CORREIA-NETO et al., 2015), sobre modelos de colaboração em tempos de Web 2.0, a presente pesquisa optou por utilizar o modelo i3C, devido à sua maior aderência ao objetivo da pesquisa e atualidade. Assim, à luz do modelo $\mathrm{i} 3 \mathrm{C}$ buscou-se responder à seguinte pergunta de pesquisa: quais as principais funcionalidades, características e limitações das ferramentas de eparticipação e e-colaboração disponibilizadas por organismos governamentais brasileiros? A partir desse contexto e usando o modelo i3C como lente de análise, o presente estudo objetivou analisar o nível de interatividade das plataformas de e-participação e e-colaboração governamentais disponibilizadas no Brasil.

Este trabalho está organizado da seguinte forma a partir dessa introdução: a seção 2 apresenta uma Revisão da Literatura acerca dos temas que embasam o trabalho e a seção 3 discorre sobre a metodologia utilizada na pesquisa. Já na seção 4 são apresentados e discutidos os resultados da pesquisa. Por fim, a seção 5 reflete sobre as principais conclusões do estudo.

\section{Revisão da Literatura}

\subsection{Ferramentas de e-participação}

O Brasil adota um regime político democrático, modelo de governo que vem sofrendo sinais de desgaste (FREITAS, 2015). Mas com o surgimento e aprimoramento da Internet e a evolução das TICs, passam a existir novos meios que visam promover uma sociedade mais democrática e participativa, através da participação e colaboração eletrônica ou e-participation e e-collaboration.

Logo após o surgimento da Web 2.0, termo cunhado em 2005 para se referir a uma nova geração de tecnologias que permite uma comunicação com maior nível de interatividade e colaboração através da Internet, oferecendo recursos e serviços para aplicações online e multimídia (BRESSAN, 2007), surgiram inúmeras plataformas como redes sociais, blogs, chats e wikis, entre outras, incluindo as ferramentas de e-participation e e-collaboration.

Essas plataformas servem para auxiliar o cidadão a contribuir nas tomadas de decisão da administração pública através de sites e aplicativos, nos quais o cidadão pode opinar sobre um projeto de lei ou enviando suas próprias ideias, sugestões para melhorias e leis, com objetivo de aprimorar o meio em que vive. Plataformas como Colab.re, e-Cidadania, Participa.br, VOTENAWEB e outras disponibilizam mecanismos para que os cidadãos tomem conhecimento das ideias da administração pública, permitindo que os mesmos expressem sua aprovação ou desaprovação, trocando ideias com o poder público e com outros cidadãos. Com o objetivo de criar essas plataformas, as organizações têm a possibilidade de utilizar o modelo 3C de colaboração apresentado a seguir.

\subsection{Modelo 3C de colaboração}

Conforme citado na Introdução, um dos mais utilizados modelos de colaboração é o 3C, delineado na Figura 1. No modelo original (ELLIS; GIBBS; REIN, 1991), os sistemas de groupware eram dispostos em três dimensões (comunicação, coordenação e colaboração) que juntas formavam a cooperação; mais tarde esse modelo deu origem ao modelo 3C de colaboração (FUKS; RAPOSO; GEROSA, 2003), realçando a colaboração como construto maior e que era formado pelas dimensões comunicação, coordenação e cooperação. 
Figura 1: Modelo 3C de Colaboração

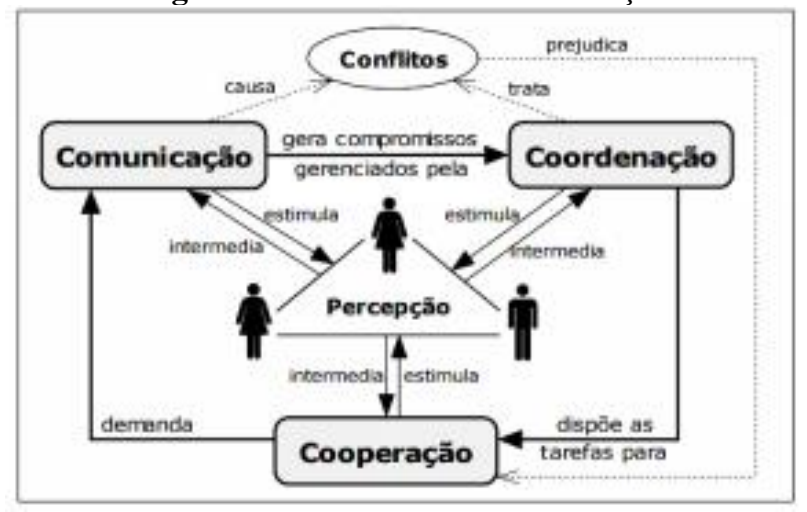

Fonte: Fuks, Raposo e Gerosa (2003)

$\mathrm{O}$ modelo $3 \mathrm{C}$ de colaboração foca nos aspectos importantes para se analisar cada dimensão da colaboração, todavia, para que exista de fato a colaboração, é necessário que as três dimensões se relacionem. Sendo assim, a comunicação se caracteriza pela troca de mensagens, a coordenação por intermediar o processo para o gerenciamento de recursos e pessoas e a cooperação é caracterizada pela atuação em conjunto no espaço compartilhado para a produção de objetos ou informações (FUKS; PIMENTEL, 2011).

De acordo com o dicionário Aulete (2017), em sua versão digital, comunicação é conceito, capacidade, processo e técnica de transmitir e receber ideias, mensagens, com vistas à troca de informações, instruções etc. No contexto eletrônico, a comunicação é considerada produtiva quando um emissor é informado de que a sua mensagem foi recebida pelo receptor. Nos sistemas colaborativos a comunicação abrange tudo o que envolve a troca de mensagens entre usuários numa plataforma.

Ainda seguindo o dicionário Aulete (2017), cooperação é a ação de cooperar, prestar auxílio para um fim comum e, dessa forma, a cooperação estabelece como os membros de um grupo cooperam, produzem, manipulam e organizam informações no mundo eletrônico, desenvolvendo artefatos cooperativamente e relacionado as ações que permitem que os usuários cooperem na sustentação da plataforma. Por fim, coordenação envolve a préarticulação das tarefas, o gerenciamento do andamento das mesmas e a pós-articulação, envolvendo as ações necessárias para preparar a colaboração, definindo os objetivos, a escolha dos e-participantes, a separação das atividades entre eles, etc (FUKS; RAPOSO; GEROSA, 2003).

A coordenação embarca no ambiente colaborativo, permitindo aos participantes organizar e gerenciar atividades, recursos e pessoas na plataforma. É o ato de trabalhar em conjunto harmoniosamente, onde os participantes trabalham em suas atividades em conjunto para chegar a um objetivo comum, definido inicialmente (MALONE; CROWSTON, 1990). Boa parte dessas características das dimensões apresentadas são essenciais e podem ser rapidamente identificadas nas plataformas de colaboração e participação eletrônica, entretanto, um novo modelo, proposto por Correia-Neto (2014) surge como modelo atualizador do 3C e aponta novas características que surgiram com a $\mathrm{Web} 2.0$.

\subsection{Modelo i3C de colaboração}

Esse modelo, que se baseia no modelo 3C, apresentado na seção anterior, mas o atualiza trazendo a presença de mais um elemento nessas plataformas Web 2.0, a interatividade, também presente em softwares colaborativos. Através da Figura 2, é possível visualizar a interatividade no contexto do modelo 3C de colaboração.

Para Lemos (2000, p. 73, apud Correia-Neto, 2014b), interatividade é "um caso específico de interação, a interatividade digital, compreendida como um tipo de relação entre o tecnológico e o social, um diálogo entre o homem e a máquina, mediado por interfaces gráficas e em tempo real". Ainda segundo Correia-Neto et al. (2014), as plataformas de colaboração precisam aumentar o engajamento entre os participantes e seus objetos para conseguirem alcançar os objetivos traçados pelo grupo através de caminhos mais interativos. Assim, a interatividade surge da evolução do nosso meio de comunicação, que propiciou o surgimento de diversas ferramentas que, cada vez mais, vêm ganhando espaço.

Vale ressaltar ainda que a interatividade trata o intercâmbio online e instantâneo de informações, de forma 
intuitiva entre dois ou mais usuários, aumentando o rendimento da produção do usuário e motivando o usuário a participar e colaborar nesse ambiente eletrônico.

Figura 2: Modelo i3C

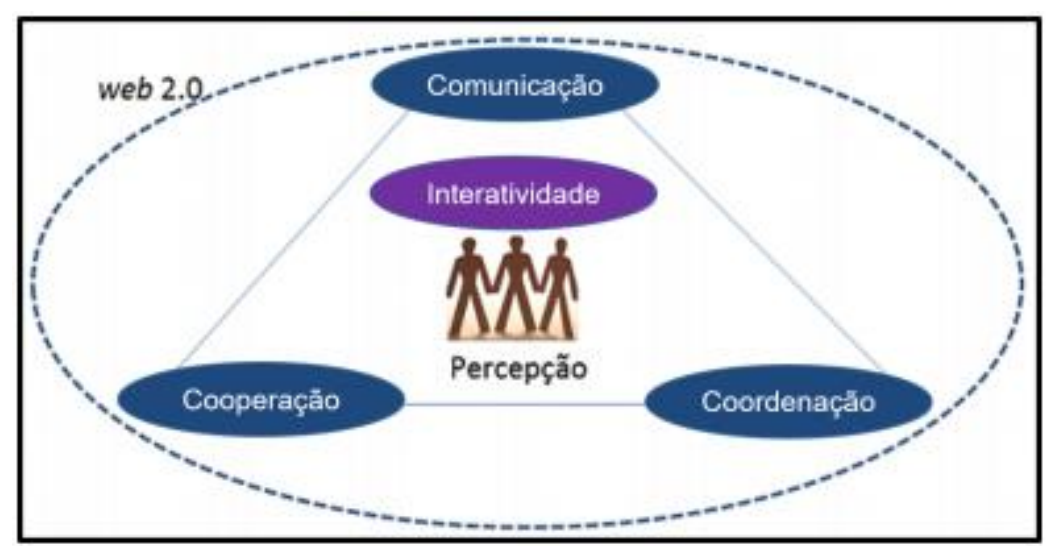

Fonte: Correia-Neto, 2014

\subsection{Trabalhos Relacionados}

O artigo desenvolvido por Filippo et al. (2007), relaciona técnicas colaborativas com ambientes de realidade virtual (RV) e realidade aumentada (RA), utilizando o modelo 3C de colaboração (FUKS; RAPOSO; GEROSA, 2003) como lente de análise. Tratando os ambientes colaborativos de RA e RV sob a visão de sistemas colaborativos, direcionados para apoiar o trabalho em grupo, os autores apresentam e discutem ambientes que exploram as particularidades dessas tecnologias quando aplicados a diferentes dimensões do modelo $3 \mathrm{C}$ de colaboração.

O trabalho realizado por Correia-Neto et al. (2014) analisou a plataforma da montadora Local Motors através do modelo $3 \mathrm{C}$ de colaboração com o objetivo de verificar o intuito das funcionalidades disponibilizadas por essa plataforma colaborativa. Nesse estudo acerca de uma plataforma de e-colaboração que reúne mais de 30.000 engenheiros, designers e entusiastas de automóveis, os autores afirmam que foi possível visualizar algo além do modelo 3C. Nesta nova visão, os autores relatam que a interatividade informática criou uma nova modalidade comunicacional onde a mensagem é modificável, na medida em que responde às solicitações daquele que a consulta reforçando o sentido de participação, intervenção, bidirecionalidade e multiplicidade de conexões. Ao final, os autores concluem que, permeando as funcionalidades disponibilizadas na plataforma colaborativa disponibilizada, foi possível visualizar algo além do modelo $3 \mathrm{C}$, a interatividade, e que no estudo de caso analisado, não parece ser possível descrever as ações realizadas dentro de ambientes colaborativos no contexto da Web 2.0 sem este importante elemento.

Ambos os trabalhos demonstram a pertinência do modelo i3C como lente de análise do fenômeno das plataformas de e-colaboração. A contribuição do presente estudo está na análise de uma plataforma que foge do contexto apresentado nesta seção.

\section{Método}

Com relação aos objetivos, as pesquisas podem ser classificadas como exploratórias, descritivas e explicativas (GIL, 1999). A pesquisa descritiva, que é a que mais se adéqua à presente pesquisa, pois tem como objetivo detalhar as características de uma determinada população ou fenômeno, observando, registrando, analisando e correlacionando fatos ou fenômenos sem manipulá-los e sem interferir naquela realidade e (BERVIAN, 2007; LEÃO, 2006). Quanto às abordagens, as pesquisas são tipicamente agrupadas como quantitativas ou qualitativas e englobam diversos métodos utilizados na pesquisa empírica (MINAYO; SANCHES, 1993). Nesta pesquisa o fenômeno estudado pedia uma abordagem qualitativa, que se utiliza de estratégias indutivas e conceitos sensibilizantes para estudar contextos sociais específicos (FLICK, 2009).

Como esta pesquisa teve o intuito analisar as funcionalidades existentes nas ferramentas de e-participação e ecolaboração, a partir do modelo i3C de colaboração, foram desenvolvidas as três etapas delineadas na Figura 3.

Figura 2: Etapas do processo de coleta e classificação das plataformas. 


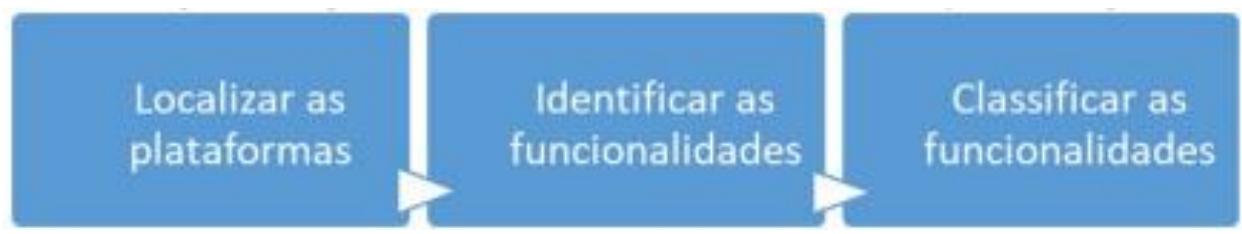

- Localizar as plataformas: nesta etapa foram realizadas duas atividades, a de buscar pelo maior número possível de páginas e aplicativos relacionados com participação eletrônica, seguindo recomendações e sugestões recebidas pelas páginas da web ou loja de aplicativos do Google, nos períodos de 28 de outubro de 2016 a 26 de dezembro de 2016 e 25 de fevereiro de 2017 a 30 de maio de 2017. A loja de aplicativos do Google foi escolhida por ter a maior quantidade de aplicativos móveis disponíveis para download, com 1,43 milhões de aplicativos registados na loja, em 2014 (Olhar Digital, 2015). Além disso, tem a maior adesão em termos de sistema operacional móvel, pois em novembro de 2016 foram registrados $93,5 \%$ de participação no mercado brasileiro do sistema operacional Android (Kantar World Panel, 2015). A segunda atividade foi a de coletar as informações públicas disponíveis das plataformas, como quantidade de acessos por mês, que foram obtidas através da página (SIMILARWEB, 2016), dentre outras características coletadas. Tal atividade foi o ponto inicial da pesquisa e a base para se prosseguir para a próxima etapa;

- Identificar funcionalidades: nesta etapa cada plataforma foi testada com perfil de usuário comum e foram elicitadas as funcionalidades de cada plataforma e capturada sua descrição de uso. Na seção de Resultados é possível visualizar as funcionalidades encontradas nas plataformas, mostradas em forma de tabela;

- Classificar as funcionalidades: após a elicitação, as funcionalidades das plataformas foram separadas e reordenadas tomando como base o modelo i3C de colaboração. Nessa fase dois pesquisadores analisaram as funcionalidades identificadas e as classificaram, mas quando havia divergência, tentava-se entrar em consenso e, caso necessário, uma terceira opinião conclui a decisão.

\section{Resultado e Discussões}

Foram identificadas e catalogadas dezessete plataformas, apresentadas na Tabela 1. A coluna "Tipo" informa se a mesma se refere a participação ou colaboração; "Status" apresenta a quantidade de acessos a suas páginas na Internet, entre os meses de março e maio de 2017 e; "Downloads" aponta a quantidade de downloads realizados na loja de aplicativos do Google até o mês de maio de 2017. Vale salientar que algumas plataformas não disponibilizavam um aplicativo móvel e, nestes casos, utilizou-se um "“-" para informar que essa categoria não se aplica a essa plataforma. Para melhor entendimento das informações pertencentes às plataformas encontradas, foi desenvolvido um breve resumo de cada plataforma, baseado em informações disponíveis em páginas da Internet, nas redes sociais da plataforma ou de sua própria desenvolvedora, que está apresentado a seguir:

e-Cidadania (Senado): é formado pelas ferramentas Ideia Legislativa, que permite enviar e apoiar ideias dos senadores e onde o usuário pode visualizar uma lista com todas as ideias enviadas ou pesquisar, junto com a quantidade de apoios que cada uma já recebeu. Com 20 mil apoios uma proposta já é encaminhada à Comissão de Direitos Humanos e Legislação Participativa $(\mathrm{CDH})$ para receber parecer dos senadores; Evento Interativo, para participar de audiências públicas com a transmissão ao vivo e espaço para publicação de comentários; Consulta Pública, que permite ao usuário dar sua opinião sobre projetos de lei, medidas provisórias e outras proposições que tramitam no Senado Federal.

Tabela 1: Informações Públicas das Plataformas

\begin{tabular}{|l|c|c|c|c|}
\hline \multicolumn{1}{|c|}{ Nome } & Tipo & Status & Acessos & Downloads \\
\hline e-Cidadania (Senado) & Participação & Ativo & 5.060 .000 & - \\
\hline e-Democracia (Câmara) & Colaboração & Ativo & 38.710 & 1.000 \\
\hline Colab.re & Participação & Ativo & 45.190 & 50.000 \\
\hline PortoAlegre.cc & Participação & Inativo & - & - \\
\hline VOTENAWEB & Participação & Ativo & 28.930 & 1.000 \\
\hline Mudamos & Participação & Ativo & 180.920 & 100.000 \\
\hline $\begin{array}{l}\text { Ouvidoria Cidadã da Câmara Municipal da } \\
\text { Cidade Vitória de Santo Antão }\end{array}$ & Participação & Ativo & 5.000 & 500 \\
\hline Dialoga Brasil & Participação & Ativo & 5.000 & - \\
\hline Participa.br & Colaboração & Ativo & 36.080 & 1.000 \\
\hline Participa Maranhão & Participação & Inativo & 15.530 & - \\
\hline Participa Cidadão (Bahia) & Participação & Ativo & 0 & 50 \\
\hline Participa Campinas & Participação & Inativo & - & 100 \\
\hline
\end{tabular}


Desempenho Acadêmico e Uso de Tecnologias de Informação e

\begin{tabular}{|l|l|c|c|c|}
\hline Avaaz & Participação & Ativo & 6.710 .000 & - \\
\hline Plamob Olinda & Participação & Ativo & 0 & - \\
\hline SP 156 & Participação & Ativo & 54.860 & 10.000 \\
\hline Participa Cidadão (Cabo Verde-MG) & Participação & Ativo & 29.700 & 100 \\
\hline Kit Urbano (18 Cidades brasileiras) & Participação & Ativo & - & 10 \\
\hline
\end{tabular}

Fonte: dados da pesquisa (2017)

e-Democracia (Câmara): é uma iniciativa da Câmara dos Deputados que visa incentivar a participação da sociedade no debate de temas importantes para o país, por meio da Internet. As discussões são acompanhadas pelos parlamentares envolvidos com a matéria. A plataforma é dividida em duas partes: Comunidades Legislativas, onde é possível participar de debates de temas específicos, normalmente relacionados com projetos de lei já existentes; e Espaço Livre, onde a população pode definir um tema para debate e iniciar a discussão.

Colab.re: permite que prefeituras cadastradas interajam com seus cidadãos por meio das plataformas mobile e web. A ferramenta permite acompanhar problemas relatados pelos usuários e ainda permite que os usuários proponham ideias sobre o que pode ser melhorado em determinados pontos da cidade, acompanhem ideias e apoiem as solicitações de outros usuários, fortalecendo suas ideias. Também é possível dar sua avaliação sobre algum local.

PortoAlegre.cc: é a concretização do conceito de Wikicidade. Criado pela empresa Lung a partir de um projeto com a Unisinos, este conceito se refere a uma plataforma digital que permite a discussão da história, a realidade e o futuro de territórios específicos. É um espaço para discutir a capital gaúcha, mostrando o que ela tem de bom e o que precisa ser melhorado, e chamar as pessoas para ajudarem a transformar essa ideia em realidade.

VOTENAWEB: O VOTENAWEB é uma página na Internet criada para publicação dos projetos de lei do Congresso Nacional, onde o cidadão pode conhecer os projetos através de um breve resumo e votar, simbolicamente, se concorda ou não com as proposições dos parlamentares. Além disso, os usuários podem comparar seus votos entre si e com os dos deputados e senadores.

Mudamos: é uma plataforma online que permite que os usuários opinem sobre temas importantes de interesse público, ajudando na construção democrática de soluções, criando um debate informado com a participação de pessoas de vários setores da sociedade. As contribuições dadas nos debates são compiladas em documentos que são entregues diretamente aos agentes públicos responsáveis por sua implementação.

Ouvidoria Cidadã da Câmara Municipal Vitória de Santo Antão-PE: é uma página simples, onde o usuário indica onde está ocorrendo algum problema no mapa, descreve o tipo do problema e informa seus dados pessoais e de contato. O usuário ainda pode carregar uma foto.

Dialoga Brasil: é uma ferramenta de participação digital que coleta ideias e sugestões para melhorar os programas do governo federal. Apresenta temas e programas prioritários do governo federal para que a população proponha melhorias nas políticas públicas e curta propostas de outros participantes.

Participa.br: é uma plataforma federal de participação social para cidadãos, redes, movimentos sociais e organizações que querem dialogar com o governo federal na construção de políticas públicas. É uma rede social que integra ferramentas como blog, portfólio online, CMS para sites, RSS, fóruns, chats, eventos e compartilhamento de ideias em um mesmo sistema. Também oferece um espaço para usuários manifestarem suas opiniões e para debates.

Participa Maranhão: é um sistema de participação do Estado do Maranhão, com informações sobre Orçamento Participativo e Plano Plurianual, Conselhos, Conferências e outros espaços de consulta e controle social, onde o cidadão poderá participar de decisões referentes a ações de governo e propor debates e soluções. Apesar de semelhante, essa plataforma conta com a parceria técnica da equipe do Participa.br e ambas foram desenvolvidas com software livre.

Participa Cidadão: é um aplicativo, em fase experimental, destinado a fomentar a interação do cidadão com a Câmara de Vereadores de sua cidade e com os temas públicos mais frequentes. Através de um mapa colaborativo a população pode identificar problemas em seu bairro e assim cobrar uma solução da prefeitura.

Participa Campinas: é um canal de comunicação entre a Secretaria de Planejamento da Prefeitura de Campinas e a população no processo de revisão da legislação urbanística. Permite acompanhar o trabalho que está sendo feito e participar ativamente das atividades propostas para construir uma cidade melhor.

Avaaz: capacita milhões de pessoas, em todas as esferas da vida, para tomar medidas sobre questões globais, 
regionais e nacionais urgentes, da corrupção e da pobreza aos conflitos e às mudanças climáticas. Seu modelo de organização na Internet permite que milhares de esforços individuais, ainda que pequenos, tornem-se uma poderosa força coletiva.

Plamob Olinda: O Plano de Mobilidade Urbana é o principal instrumento de planejamento dos sistemas de circulação e transporte. Pelo Plano são definidas propostas e diretrizes, também em formato de lei, para que Olinda, no futuro, tenha uma mobilidade de melhor qualidade, seguindo o que já determina o Plano Diretor Municipal. Assim, os recursos são usados de forma correta com as reais necessidades e dinâmica da cidade.

SP 156: esse aplicativo permite que cidadãos contribuam e participem da gestão da cidade de São Paulo a partir da solicitação de serviços, fiscalização, denúncias, elogios, reclamações e sugestões à administração pública municipal. Permite que o cidadão acompanhe o status da sua solicitação, anexe fotos e avalie o serviço prestado.

Participa Cidadão (Cabo Verde-MG): serve para que o cidadão possa reclamar, sugerir, denunciar e elogiar, entre os muitos serviços prestados por várias entidades caboverdianas.

Kit Urbano (18 Cidades brasileiras): é uma empresa argentina que oferece uma proposta de soluções criativas e inovadoras orientadas a cobrir necessidades das cidades e cidadãos. Facilita a participação cidadã, entre a gestão de governo e os cidadãos, através de aplicativos para cada a cidade e também de uma ferramenta inovadora de gestão para o município. Seu funcionamento se assemelha ao da Colab.re, mas a empresa cria um aplicativo para cada cidade que atua, seguindo o mesmo modelo. No Brasil são mais de 18 cidades que já utilizam os serviços da Kit Urbano.

A Figura 4 apresenta as funcionalidades encontradas em todas as plataformas que foram testadas utilizando um perfil público de cada plataforma. Na Tabela 2 é possível visualizar quais plataformas possuem funcionalidades de coordenação, salientando que é utilizado o termo utilizado pela própria plataforma para se referir a essas funcionalidades, como no caso do e-Democracia, que utiliza o termo "Favoritar" para representar a funcionalidade Seguir.

Figura 3: Funcionalidades encontradas nas plataformas

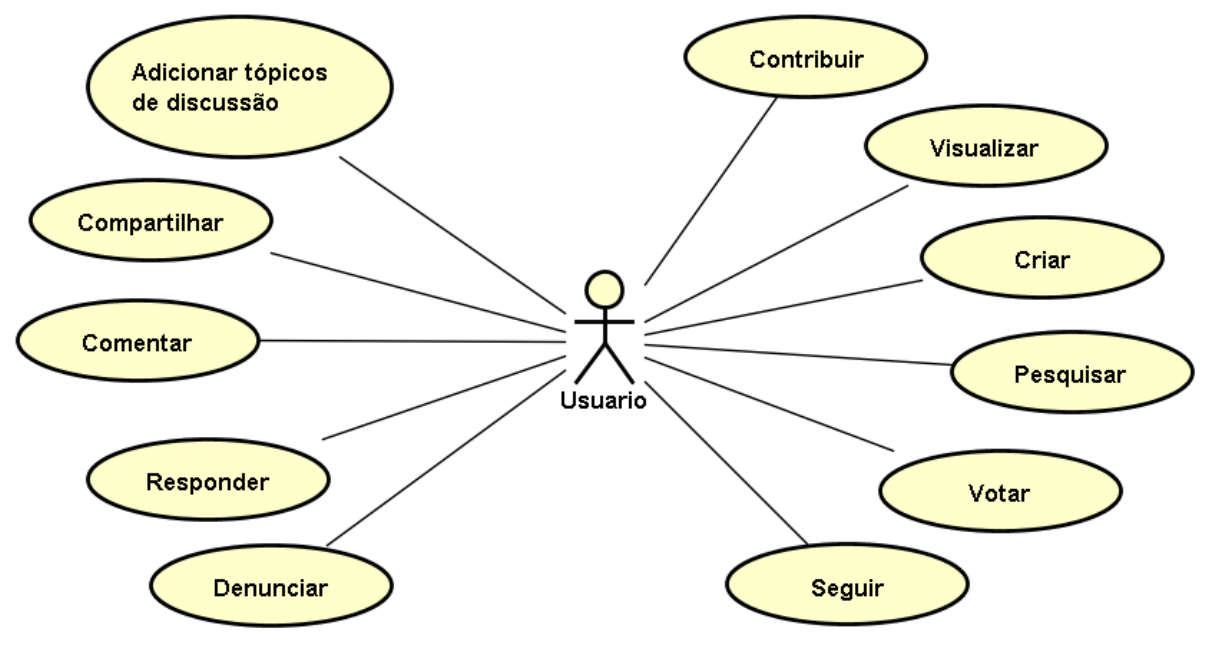

Fonte: dados da pesquisa (2017)

Ou ainda, o termo usado para complementar a funcionalidade, como no caso da Colab.re, que foi usado o termo "Publicação", para mostrar que a plataforma possui uma funcionalidade "Criar Publicação". Em alguns casos esses espaços podem estar representados pelo termo "Inativo", que significa que no momento da classificação ou análise dessa plataforma, a mesma não estava funcionando corretamente ou estava descontinuada. $\mathrm{O}$ termo "Não" é usado quando uma plataforma não possui essa funcionalidade.

Tabela 2: Funcionalidades de coordenação

\begin{tabular}{|l|l|l|l|l|}
\hline \multicolumn{1}{|c|}{ Nome } & \multicolumn{1}{|c|}{ Criar } & \multicolumn{1}{c|}{ Visualizar } & \multicolumn{1}{c|}{ Seguir } & Pesquisar \\
\hline e-Cidadania (Senado) & Lei & Sim & Não & Sim \\
\hline e-Democracia (Câmara) & Tópico & Sim & Favoritar & Sim \\
\hline Colab.re & Publicação & Sim & Não & Não \\
\hline PortoAlegre.cc & Inativo & Inativo & Inativo & Inativo \\
\hline VOTENAWEB & Não & Sim & Sim & Sim \\
\hline
\end{tabular}


Desempenho Acadêmico e Uso de Tecnologias de Informação e Comunicação: Uma Análise com Estudantes de Graduação do Nordeste Brasileiro Revista Gestão.Org, v. 15, Edição Especial, 2017. p. 147-156

ISSN 1679-1827 http://www.revista.ufpe.br/gestaoorg

\begin{tabular}{|l|l|l|l|l|}
\hline Mudamos & Não & Sim & Não & Não \\
\hline $\begin{array}{l}\text { Ouvidoria Cidadã da Câmara Municipal } \\
\text { da Cidade Vitória de Santo Antão }\end{array}$ & Proposta & Sim & Não & Sim \\
\hline Dialoga Brasil & Sim & Sim & Não & Não \\
\hline Participa.br & Comunidade & Sim & Sim & Sim \\
\hline Participa Maranhão & Inativo & Inativo & Inativo & Inativo \\
\hline Participa Cidadão (Bahia) & Sim & Sim & Não & Sim \\
\hline Participa Campinas & Inativo & Inativo & Inativo & Inativo \\
\hline Avaaz & Uma petição & Sim & sim & Não \\
\hline Plamob Olinda & Não & Não & Não & Não \\
\hline SP 156 & Sim & Não & Não & Não \\
\hline Participa Cidadão (Cabo Verde-MG) & Sim & Não & Não & Não \\
\hline Kit Urbano (18 Cidades brasileiras) & Sim & Sim & Não & Sim \\
\hline
\end{tabular}

Fonte: dados da pesquisa (2017)

As funcionalidades de cooperação servem para que os membros de um grupo cooperem manipulando, organizando informações e construindo com a participação do grupo. Esse aspecto é identificado apenas na funcionalidade "Denunciar", que está disponível na Tabela 3, juntamente com as funcionalidades de comunicação.

As quatro funcionalidades de interatividade podem ser encontradas na Tabela 4, que elenca a presença dessas funcionalidades em cada uma das dezessete plataformas.

Tabela 3: Funcionalidades de cooperação e comunicação

\begin{tabular}{|l|c|c|c|}
\hline \multicolumn{1}{|c|}{ Nome } & Denunciar & Votar & Adicionar Tópicos \\
\hline e-Cidadania (Senado) & Não & Apoiar & Não \\
\hline e-Democracia (Câmara) & Sim & Sim & Sim \\
\hline Colab.re & Sim & Apoiar & Não \\
\hline PortoAlegre.cc & Inativo & Inativo & Inativo \\
\hline VOTENAWEB & Sim & Sim & Não \\
\hline Mudamos & Não & Assine & Não \\
\hline $\begin{array}{l}\text { Ouvidoria Cidadã da Câmara Municipal } \\
\text { da Cidade Vitória de Santo Antão }\end{array}$ & Não & Não & Não \\
\hline Dialoga Brasil & Não & Sim & Não \\
\hline Participa.br & Sim & Sim & Sim \\
\hline Participa Maranhão & Inativo & Inativo & Inativo \\
\hline Participa Cidadão (Bahia) & Não & Não & Não \\
\hline Participa Campinas & Inativo & Inativo & Inativo \\
\hline Avaaz & Sim & Assinar & Não \\
\hline Plamob Olinda & Não & Sim & Não \\
\hline SP 156 & Não & Não & Não \\
\hline Participa Cidadão (Cabo Verde-MG) & Não & Não & Não \\
\hline Kit Urbano (18 Cidades brasileiras) & Não & Apoiar & Não \\
\hline
\end{tabular}

Fonte: dados da pesquisa (2017)

Tabela 4: Funcionalidades de interatividade

\begin{tabular}{|l|c|c|c|c|}
\hline \multicolumn{1}{|c|}{ Nome } & Comentar & Responder & $\begin{array}{c}\text { Compartilhar nas } \\
\text { redes sociais }\end{array}$ & Contribuir \\
\hline e-Cidadania (Senado) & Sim & Não & Não & Não \\
\hline e-Democracia (Câmara) & Sim & Sim & Sim & Sim \\
\hline Colab.re & Sim & Não & Não & Sim \\
\hline PortoAlegre.cc & Inativo & Inativo & Inativo & Inativo \\
\hline VOTENAWEB & Sim & Sim & Sim & Não \\
\hline Mudamos & Não & Não & Não & Não \\
\hline $\begin{array}{l}\text { Ouvidoria Cidadã da Câmara Municipal } \\
\text { da Cidade Vitória de Santo Antão }\end{array}$ & Não & Não & Não & Sim \\
\hline Dialoga Brasil & Não & Não & Não & Não \\
\hline
\end{tabular}


Santos, J. A. P.; Correia Neto, J. S.; Souza, E.

http://www.revista.ufpe.br/gestaoorg

\begin{tabular}{|c|c|c|c|c|}
\hline Participa.br & Sim & Não & Não & Não \\
\hline Participa Maranhão & Inativo & Inativo & Inativo & Inativo \\
\hline Participa Cidadão (Bahia) & Não & Não & Não & Sim \\
\hline Participa Campinas & Inativo & Inativo & Inativo & Inativo \\
\hline Avaaz & Não & Não & Não & Sim \\
\hline Plamob Olinda & Não & Não & Não & Não \\
\hline SP 156 & Não & Não & Não & Sim \\
\hline Participa Cidadão (Cabo Verde-MG) & Não & Não & Não & Sim \\
\hline Kit Urbano (18 Cidades brasileiras) & Sim & Não & Não & $\operatorname{Sim}$ \\
\hline
\end{tabular}

Fonte: dados da pesquisa (2017)

Os resultados apontam que em cada ferramenta foi possível identificar em média seis funcionalidades que estão disponíveis para todos os usuários. Vale destacar que, para chegar a essa média foram consideradas apenas as plataformas ativas, que tiveram o número de funcionalidades maior que zero. Dentre as ferramentas com mais funcionalidades destacam-se as seguintes: e-Democracia e Participa.br com 11 funcionalidades cada uma, seguida da VOTENAWEB com 10 funcionalidades. Pode-se afirmar que apenas uma das dezessete ferramentas, possui todas as funcionalidades que representam a interatividade, apontado por Correia-Neto (2014) como importante nesse contexto, nesse caso, a plataforma e-democracia.

Após coletar e categorizar essas informações sobre cada plataforma, foi possível notar que a plataforma internacional Avaaz é a que possui mais acessos mensais, com pouco mais de seis milhões de acessos no mês de maio de 2017, seguido da plataforma e-cidadania, que é a que possui mais adesão do público brasileiro, com aproximadamente cinco milhões de acessos no mesmo período. Vale ressaltar que nas páginas das plataformas Plamob Olinda e Participa Cidadão (Bahia) não foi possível contabilizar seu acesso com a ferramenta usada nessa pesquisa.

No caso da página Kit Urbano, também foi decidido não contabilizá-la, pois a própria foi desenvolvida visando oferecer suas soluções de aplicativos de participação e colaboração eletrônica para a área da administração pública de uma cidade ou estado por exemplo, não oferecendo funcionalidades para o cidadão como um usuário da plataforma.

É possível perceber também que os aplicativos móveis dessas plataformas vêm atualmente ganhando um pouco mais de interesse da sociedade brasileira. Onze das dezessete plataformas pesquisadas possuem um aplicativo móvel da plataforma disponível na loja de aplicativos do Google e, dessas onze, uma já alcança a faixa de 100 mil downloads na loja de aplicativos, que é o caso do aplicativo Mudamos, que no decorrer dessa pesquisa teve seu aplicativo móvel remodelado. Outras plataformas que também possuem uma boa aceitação de seu público alvo é o aplicativo da plataforma Colab.re, na faixa de 50 mil downloads, e o SP 156 que é destinado à cidade de São Paulo e possui uma faixa de 10 mil downloads na loja de aplicativos do Google, ambos consultados no mês de maio de 2017. Outro aspecto é que, dessas plataformas, dez permitem ao usuário fazer login através da sua conta do Facebook ou Google, sendo que as plataformas que mais possuem acessos mensais oferecem essa facilidade; e nesse quesito se destacam Avaaz, e-Cidadania e Mudamos. Talvez a falta dessa característica interfira na quantidade de acessos, por se tornar uma barreira ao usuário novo enfrentar um preenchimento de formulário para se cadastrar e para os usuários antigos ao tentarem se logar na plataforma.

Com relação à plataforma denominada "Kit Urbano", refere-se uma empresa desenvolvedora de soluções para cidades e, pelo fato dela mesma ser a responsável pela implementação de diversas plataformas no Brasil e no mundo, no decorrer dessa pesquisa foi possível identificar dezoito cidades brasileiras que utilizavam os serviços dessa empresa de origem argentina. Entre elas estão: São José dos Campos-SP, Pouso Alegre-MG, Santo AndréSP, Jundiaí-SP, Itaquaquecetuba-SP, Diadema-SP, Mauá-SP e Campinas-SP, entre outras. Todos os aplicativos seguem o mesmo padrão, mesmas funcionalidades e possuem poucas adaptações para cada região. Mas com oito funcionalidades, sendo três de interatividade, seus aplicativos não perdem para as demais plataformas do mercado apresentadas nesse trabalho.

\section{Conclusões}

Com esses resultados da pesquisa é possível identificar as funcionalidades das plataformas de participação e colaboração eletrônica de forma mais eficiente, quais atendem às necessidades dos usuários e as deficiências que podem ser melhoradas, assim como podem ser usados como base no desenvolvimento de novas ferramentas.

Em relação à quantidade de plataformas de e-participação nacionais catalogadas, pode-se afirmar que é um número consideravelmente baixo, se levarmos em consideração que muitos Estados e cidades brasileiras 
Desempenho Acadêmico e Uso de Tecnologias de Informação e

preferem manter suas próprias plataformas, ao invés de contratar uma plataforma como a Colab.re, que pode ser usada por qualquer cidade, por meio de uma assinatura paga, por isso supõe-se que o número de plataformas deveria ser bem maior.

Ainda podem ser estudados outros critérios que engajam os usuários, fazendo-os permanecerem usando frequentemente essas plataformas. Por exemplo: recompensas reais, como isenção de tributos, descontos em estabelecimentos e prêmios que simbolizem gratificação pela participação cidadã; ou reconhecimento simbólico na comunidade virtual ou real, entre outros, que não foram identificados na maioria das plataformas pesquisadas.

\section{Referências}

AULETE. Dicionário Caldas Aulete. 2017. Disponível em: (http://www.aulete.com.br/).

BERVIAN, P. CERVO. AL. [S.1.: s.n.], 2007.

BRESSAN, R. T. U. Dilemas da rede: Web 2.0, conceitos, tecnologias e modificações. Intercom, 2007.

CORREIA-NETO, J. S. Colaboração em processos suportados pela web 2.0: a emergência da interatividade. 234 p. Tese (Doutorado) - Universidade Federal de Pernambuco, 2014.

CORREIA-NETO, J. S. et al. Além do modelo 3C em plataformas de colaboração: o caso da montadora Local Motors. n. NOVEMBER, 2014.

CORREIA-NETO, J. S. et al. Where are the collaboration models? Findings from a Systematic Mapping Study. p. 1-8, 2015.

DINIZ, E. H. et al. O governo eletrônico no Brasil: perspectiva histórica a partir de um modelo estruturado de análise. Revista de Administração Pública, v. 43, n. 1, p. 23-48, 2009. ISSN 0034-7612.

ELLIS, C. A.; GIBBS, S. J.; REIN, G. Groupware: Some issues and experiences. Commun. ACM, ACM, New York, NY, USA, v. 34, n. 1, p. 39-58, jan. 1991. ISSN 0001-0782.

FILIPPO, D. et al. Ambientes colaborativos de realidade virtual e aumentada. C. Kirner, R. Siscoutto, EDS, p. 168-191, 2007.

FLICK, U. Introdução à Pesquisa Qualitativa-3. [S.1.]: Artmed Editora, 2009.

FREIRE, G. M. C. d. A. et al. O ciberativismo na construção da ciberdemocracia: análise do portal wikicidade de Porto Alegre. p. 219-231, 2011. ISSN 1850-2814.

FREITAS, J. L. Participação Eletrônica, Transparência E Accountability No Gabinete Digital Sob a Lente Da Teoria Da Ação Comunicativa. p. 151, 2015.

FUKS, H.; PIMENTEL, M. Sistemas colaborativos. [S.1.]: Elsevier Brasil, 2011.

FUKS, H.; RAPOSO, A. B.; GEROSA, M. A. Do Modelo de Colaboração 3C à Engenharia de Groupware. Simpósio Brasileiro de Sistemas Multimídia e Web, v. 1, p. 8, 2003.

GIL, A. C. Métodos e técnicas de pesquisa social, 1999. v. 264.

Kantar World Panel. Smartphone OS sales market share. 2015. Disponível em: (http://www.kantarworldpanel.com/global/smartphone-os-market-share/).

LEÃO, L. M. Metodologia da pesquisa aplicada as ciências naturais. [S.1.: s.n.], 2006.

MACINTOSH, Ann. Characterizing e-participation in policy-making. In: System Sciences, 2004. Proceedings of the 37th Annual Hawaii International Conference on. IEEE, 2004.

MALONE, Thomas W.; CROWSTON, Kevin. What is coordination theory and how can it help design cooperative work systems? In: Proceedings of the 1990 ACM conference on Computer-supported cooperative work. ACM, 1990.

MEDAGLIA, R. eparticipation research: Moving characterization forward (2006-2011). Government Information Quarterly, v. 29, n. 3, p. 346 - 360, 2012. ISSN 0740-624X.

MINAYO, Maria Cecilia de S.; SANCHES, Odécio. Quantitative and qualitative methods: opposition or complementarity?. Cadernos de saúde pública, v. 9, n. 3, p. 237-248, 1993.

Olhar Digital. Google Play finalmente supera a App Store em número de aplicativos. 2015.

SIMILARWEB. SimilarWeb - Digital Market Intelligence \& Website Traffic. 2016. 